\title{
The Four Symmetries "A Study of the Shape Characteristics and Expressive Connotations of the Dwelling"
}

\author{
${ }^{1}$ Mutasem Azmi Al-karablieh, ${ }^{2}$ Mosab Mahmoud AL-Qudah, ${ }^{3}$ Jehad Hasan ALameri, ${ }^{4}$ Ibrahim Ahmad AL- \\ Khatib, ${ }^{5}$ Haifaa Ahmad Bani Ismail, ${ }^{6}$ Diran john Malatjalian \\ 1,2, 3,4,5,6 The University of Jordan
}

\begin{abstract}
This study seeks to study the relations and the shape characteristics and expressive connotations of the house through following it based on the relationship between shape and meaning and their association with human existence. Because it is related to his body and his idea of these relations, which are formed in his consciousness through his movement and locomotion between the blocks and the interior spaces of the house, therefore, what we see in front of us is really what we think, which gives us a sense of surprise and harmony, which explains the close relationship between the visible and the invisible in the things in front of us.

The house and the sense of it is ultimately not abstract; but it carries a broad philosophical content, and that its study from this angle, specifically (phenomenal), give it its true meaning in this world, here is the gap that the study seeks to research, in terms of experience living and sense of place and the interaction of the individual with the place and specifically housing and the internal vacuum of the place.

This study concluded that the dwelling is inseparable from the self in terms of the visual formation of the blocks and shapes; rather, the house and the body are intertwined with memories. The sight of familiarity and feeling of residence is not only born of childhood memories; but this feeling may be generated by what the dwelling impose on us of the data in the phenomenal shape of it, and therefore what the shape of the rooms achieved by central concentrates, the harmony of shape, color and texture are the ones that motivate us to enjoy the dwelling and thus can be formulated and arranged in harmony and correspondence to achieve familiarity. The availability of shape characteristics of certain patterns and systems and the provision of sufficient internal spaces contribute to a kind of affinity between the self and the subject as a whole (between the inhabitant and the inhabited), which is a necessary objective for realizing the idea of housing awareness.
\end{abstract}

Keywords: Dwelling, Shape, Sense, Place, Interior design.

DOI: $10.7176 / \mathrm{ADS} / 73-05$

Publication date:May $31^{\text {st }} 2019$

\section{Introduction}

Foucault pointed to the relationship represented by the thinker and thought, between form and content. Hence, Foucault tried to reveal the relationship between man and things. "We are in vain to say what we see because what we see never dwells in what we say, and in vain we work to make others see, with pictures, metaphors and comparisons what we say."4

Foucault, when speaking about the four symmetries ${ }^{5}$, raised the issue of symmetries between the symbols, pointing out that it was that which organized what he called the game of symbols, and thus allowed to know the visual and invisible things, and it led the art of representing and visualization it, painting mimics space and exemplification mimics perception, and Foucault linked that similar to knowledge, and considered that these symmetries impose a gap on the knowledge of similarity.

\footnotetext{
${ }^{4}$ Foucault, Michelle, (1989-1990), Words and Objects, p. 34, translated by Mataa Safadi et al, Center for National Development, Beirut

${ }^{5}$ Foucault intended four similarities: compatibility, competition, symmetry, measurement and empathy. He points out that the identity of things is their ability to resemble other objects and to approach them while preserving their privacy. They sympathize and contradict in a way that explains the evolution of things, their growth and their intermingling, Previous source, p. 45.
} 


\section{Research Goals}

This study sheds light on the place of residence and the signs of compatibility through the communication through the visual image of that place, which aims to:

1. Emphasis on the importance of the aesthetic value of the place in the interior design and its components, elements and materials as part and an important component in shaping the artistic image in the place.

2. Discover the experience of the place from the idea of dynamic imagination (artistic image and place), as a design requirement contributes to our belonging to where we live, and thus access to the aesthetic values and symbolic indications of the place to benefit from the visual embodiment of the place in the contemporary interior design.

3. The place of residence and the sense of it is ultimately not something abstract; but it carries a broad philosophical content, here is the gap that the study seeks to research, in terms of experience living and sense of place and the interaction of the individual with the place and specifically housing and the internal vacuum of the place.

\section{Research problem}

It should be noted that the study of spaces, and blocks was the main concern of the designers of the internal vacuum, where many readings and analyzes in the structure and architecture of the vacuum in search of that combination of visual spaces and shapes within the housing with what based on it of dimensions and measurements. Here we must examine whether there are clear ties in the interconnectedness of these spaces and areas of our conscience and our existence, and whether it is possible to make these different forms and diversity to embrace our ideas and desires and interests to make us prisoners, we own and dictate our desires to own that place. This is why we look at the place philosophically and drop this philosophy on the living world, by trying to answer the following questions.

\section{Technical reading in four symmetries}

The world around us is full of symmetries that come close to and belong to the same genus in the work of art, (meaning that they belong to one visual category such as color, shape and texture), which generates symmetries in detail, As well as the location of these categories and similar characteristics of nature so as to produce new symmetries that arise in the art of painting, "similarity necessitates a dialogue that believes in symmetries," 6 all signs of harmony.

The work of art as an integral whole should be part of this total congruence of the world, as competition somehow expresses the natural twin of things, it gives the opposites, the power of each other, in a battle to form itself, reflected in reflection A simple one in which one of the conflicting forms takes over the other.

As for symmetry, it talks about the bonds and controls and their links, "For example, the relationship of stars with the sky where it shimmers, and the relationship of grass to the earth, and living with the planet they inhabit, and minerals and precious stones with rocks buried in them, ${ }^{7}$ and "if the symmetry of silence and balance of different movement, emotion and dynamic, ${ }^{8 "}$ the symmetry increases the intensity of the expression of the structure and serves the task of art foundation (emotional affective effect in man).

The empathy is in the depths of the world and the soul, in that man who drives it, it is the one who has the power to stir the movement of things in the world by the convergence and dispersion which is a movement of attraction of things, "It secretly raises internal movement, ${ }^{9 "}$ It has the power to represent and to make things look identical with each other, which preserves things from their isolation.

What is represented by these four symmetries can be dropped on the arts in general, each part of this world is located in a place independent of the other, but the world which is not form is what remains in our perception and we can understand that each one homogeneous and we contemplate similar parts and competing and sympathetic and similar, and its evolution gives us a variety of molecules to make these elements come together and move together as single units.

This reproduction and repetition made seeing these things ordinary when seen, to become a natural form acceptable and recognizable, and created in our imagination that arrangement, which reaches the

\footnotetext{
${ }^{6}$ Foucault, Michelle, previous source p. 40.

${ }^{7}$ Foucault, Michelle, previous source p. 42.

${ }^{8}$ Nouri, Jihad, Art, Science and Beauty, p. 122, encyclopedia, cultural series dealing with various sciences, arts and literature, House of Public Cultural Affairs, Baghdad.

${ }^{9}$ Foucault, Michelle, previous source p. 44
} 
impressions similar to our senses, hence the organization and the automatic arrangement of the external nature is the chest of the mind, if those symmetries are not there, the imagination is hit by something of idleness and stupidity.

If we recognize the objects through the senses, the differentiation between the synonyms emerges, and this reduces the objects in their sensual appearance. This reduction is almost the same as the objects, and it has a symbolic structure that is reflected in an artistic form.

Art, by its very nature, shows these distinctions and divisions in its components, as an expression of similar values. These distinctions allow for a particular subject, position or situation. Their existence presupposes the existence of a set of artistic and philosophical theories that carry their independence in each artistic work. Implied by homogeneity of that work by the following points:

1. The fundamental meaning.

2. Harmony or as Foucault called adaptation.

3. Purity style: the sense of uniqueness of the artwork.

What Foucault tried to present when analyzing artistic work (The maidservant painting (Fig. 1)) for Diego Velasquez is the relationship between man and things, the relationship between the visual and the invisible, which he considered infinite and incapable of the visual, from here we can refer to the self-attitude towards the work of art which is in the form of Aesthetic responses as follows ${ }^{10}$ :

1. Stop

The impact of the aesthetic theme is the self-response of that subject, which is to indulge in the observation and reflection of the work of art.

\section{Isolation or unity}

Which is that the aesthetic behavior has the ability to exclude all that counts the artistic work or aesthetic theme, and here we find that in the face of the work of art, as if we have reached into a world of aesthetic stand-alone, as if we live until the outside world.

3. The feeling that we exist

It is a sense that we exist in the face of phenomena, not facts, in the sense that the aesthetic sense of realism has no apparent nature. We limit our attention to looking at the work of art, its form and appearance.

4. Intuitive position

It is that the one who leads us in aesthetic behavior is not the inference, the proof, the mental research as in science, but the intuition, the direct eye and the sudden realization. We are drawn to that work or disowned because of an obscure sense, and we are able to meditate details, and all parts of the picture are always present with you do not miss you ". ${ }^{11}$

\section{Emotional impression}

The aesthetic position is not only a position of personal response, it is a position related to conscience and emotion. This is what Foucault has pointed out in the four symmetries that it lies deep in the world and in the soul. It also makes us relate aesthetics to sensitivity rather than mental retardation.

6. Emotional adjustment or symbolic sympathy

When we judge, for example, an aesthetic theme, we place ourselves in the same position, as if we were imitating it, an internal simulation.

\footnotetext{
${ }^{10}$ Ibrahim, Zakaria, (1977), The Problem of Art, p. 185, Contemporary Philosophical Problems, Egypt Printing House, Cairo. ${ }^{11}$ Fisher, Ernest, (2002), Necessity of Art, Hala for Publishing and Distribution, p. 69 Translated by Asaad Halim, First Edition, Giza.
} 


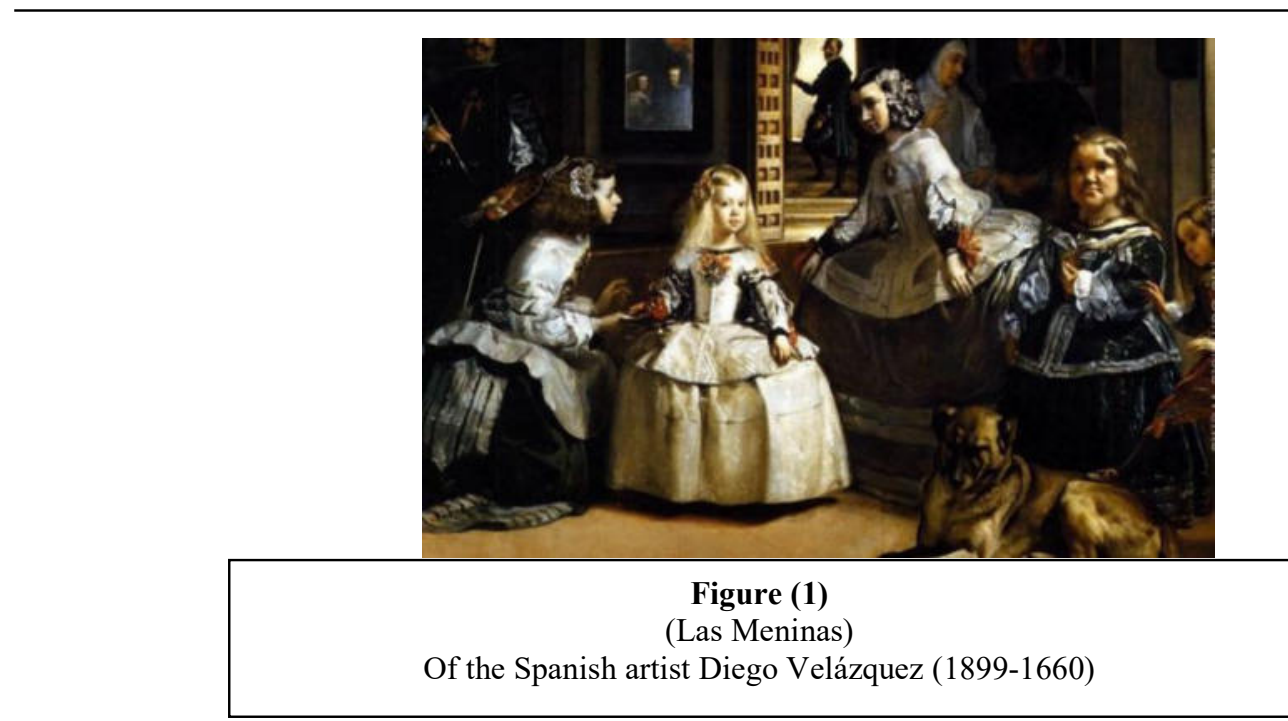

So when we meditate things, we give it something from the core of our lives, once the self takes its course in the work of art by virtue of its will, then the dye taken by meditation does not become dependent on the subject itself, the spirit of the things that are hoped is ultimately due to the same things not to the self, that the dynamism that returns to the objects when contemplated lies in the same things, and the original aesthetic act is the avoidance of self and possible subject matter, and here lies the goal of art in "the introspection of living feeling and its embodiment, and the vital participation that is a blow of emotional contact and interaction with the vital image"12

What makes art valuable is to bring every artistic phenomenon back to a certain position with links that vary in durability "discovered in the changing mirrors of artistic phenomena"13

\section{Analytical Study}

"The aesthetic experience at best seems to isolate us and the subject from the mainstream of experience," says Jerome Stolens. "We admire the subject itself, separating it from its mutual relationship with other things"14 Housing installations are a form of consciousness, in the sense that they themselves constitute a presence and a way of thinking, and integrates this awareness of those structures in the (ego). My view is made by thought or consciousness, which gives clarity to the physical nature of the world. The dwelling is full of formative structures and expressions of expression that express in their relations a means, including mass, emptiness and motion. These forms and combinations are a way to reach the intellectual goal already discussed by Heidegger, a situation of expressive phenomenon and visible multiple forms of understanding according to perceived senses. Because the dwelling is a physical thing that has a status (status), it is subject to change and movement over time. In every moment we live in it, it gives us a different perception and impression. It expresses the invisible and the imminent presence of the hiding place. For all the meaning of "imagination and the invisible does not express another visual sense, but about the hiding." What combines these combinations is their compatibility. Their symmetries in location, shape and spatial interactions make them belong to one cognitive field. They also express themselves by competing and reversing them, which gives power to one at the expense of the other, in a battle of form with itself. So that one of the forms and grabs our attention at the expense of his opponent the other form.

While its symmetry represents a strong relationship gathers it. And increases the intensity of expression structure in terms of intellectual expression of forms, symmetry serves silence and competition serves the movement, what motivates and stimulates the movement of things in us is the sympathy of those structures with their closeness and divergence, a movement of attraction to things. It stimulates an internal movement. It has the power to make things appear identical to each other, which keeps them from isolation.

Based on this understanding, our vision of the formal formations of the house makes it a natural and acceptable form, resulting in an arrangement and harmony represented in consciousness, in this organization and arrangement, things appear in their cognitive, sensory appearance, which brings us closer to things and forms their semantic structure which appears in its creative form. These distinctions and divisions are expressions and

\footnotetext{
${ }^{12}$ Abu Rayan, Muhammad, (1989), Philosophy of Beauty and the Origin of Fine Arts, Alexandria, Dar Al Maarifa , p. 3.

${ }^{13}$ Arvon, Henry, (1982), The Marxist Aesthetic, p. 6, translated by Jihad Noman, Oweidat Publications, Beirut.

${ }^{14}$ Stolens, Jerome, (1974), artistic criticism, his study of aesthetics and philosophy, translation of Fouad Zakaria, Cairo, Ain Shams University Press, p. 18.
} 
attitudes expressed through the homogeneity of the housing structures in their compatibility and meaning (Fig. 2). ${ }^{15}$

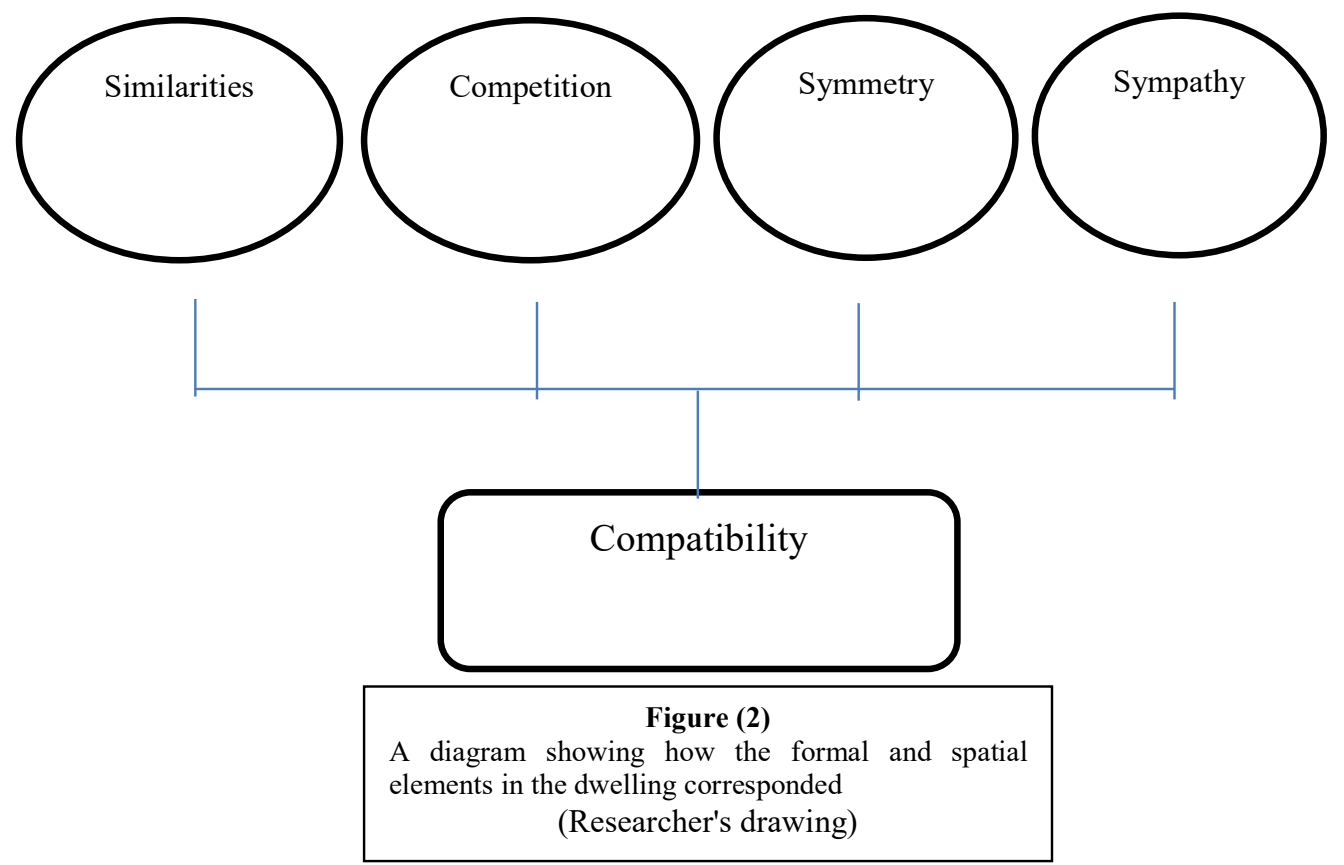

\section{Rooms and corridors}

As the form is a manifest existence in the outside world, and understood as a subject, it is connected to man by means of moral relations in his mind, and comes as a material existence as a result of human action and expressive ability, through the intentional relationship between the self and the subject (meaning of sense) So that dropping those visible forms in it is a projection of feeling. Thus, the taste of shapes and fixtures in the rooms in the dwelling requires deep attention and awareness. This is achieved by feeling the material, shape, texture, light ... and others. And the feeling of the other located in the same place. The essence of the interior design of the house of the nature of the organization of mutual relations between its direct and implicit meaning, which can be perceived intuitively in the phenomenological approach as a first step, and then they recognize the analysis of the line.

Our sense of dwelling is generated by the movement it gives us. This sensation is characterized by the rhythm of continuity, symmetry, rapprochement and spacing between those elements, as well as the sense of weight as the lightness and heaviness of the elements of the place. The material here becomes a pure expression of what we feel, and the vacuum and form of emptiness becomes the real source of the feeling of dwelling. This formation in the blocks and the vacuum in the dwelling is a result of the mixing of movement between rooms and corridors and their relationship abroad.

And the rooms in their form and distribution take a human value that enhances the sense of housing, in that it connects the windows with their wide openings and looking outward on the one hand, and between the corridors of internal movement with emotional attachment on the other hand, these rooms have enhanced selfinteraction with both interior and exterior (Fig. 3). Al-Zu'aiter's house has a unique design characteristic based on movement. This movement is reflected in regular periodicity of spaces, shapes and colors, the rhythm here can be observed in the harmony between mass and vacuum or in color or size variation in rooms and interior spaces. Formal layout of rooms has played a prominent role in showing symmetrical and repetitive formations regularly in the structural engineering of the dwelling, resulting in visual harmony of shapes and spaces and successive blocks.

\footnotetext{
${ }^{15}$ Michel Foucault used the four characteristics of compatibility (similarity, competition, symmetry and empathy) as part of his analysis of Velasquez's masterpiece, in the context of the search for signs of congruence in visual objects, so we can drop them on the dwelling and identify the relationship between man and things. See Foucault, Michelle, (1989-1990), Words and Objects, Beirut, translated by Mataa Safadi et al., Center for National Development, p.45
} 
This harmony and competition between the blocks and the vacuum gives the things of the order and open spaces a certain method of continuity; is to arrange things such as rooms and corridors on the one hand, and open spaces that give us a visual extension on the other hand, this form of organization makes us feel the interior space and interact with it. The concept of continuity in the inner space is illustrated by the central design of the rooms and their follow-up. Because visual forms express relationships, they necessarily reflect the lengths and dimensions of forms that affect our sense and our feeling, which makes us prevent them expressive qualities (such as beautiful or ugly), and proportion is a harmony in these forms visible within the spaces. The symbolism of the shapes, while carrying within them meanings that descend behind these forms to produce balanced principles and rhythms its outcome is the beauty. Awareness of the dwelling here is perception and understanding of the relationship between the whole form and the transition to the particles. The sympathy for these relations is based on the proportionality between them, in (Fig. 4), geometric forms are based on a single unit (straight lines), through which the process of procreation of the same form begins in an infinite set of regular repetitions. The importance of this is reflected in the mind as a rhythm carried by those spatial distances, lines and lengths.

Reading the design forms and distinguishing their relationships is based on perception and understanding of the dimensions and measurements of these forms and their relationship in the interior design as a whole is integrated on the basis of accuracy in choosing the appropriate length and width for each shape, and each shape and its relationship to other elements, which inevitably produces inevitable forms of compatibility in terms of form and size, to the ideal degree of aesthetics in the masses and spaces, and thus these relations dwell in the sense and feeling.
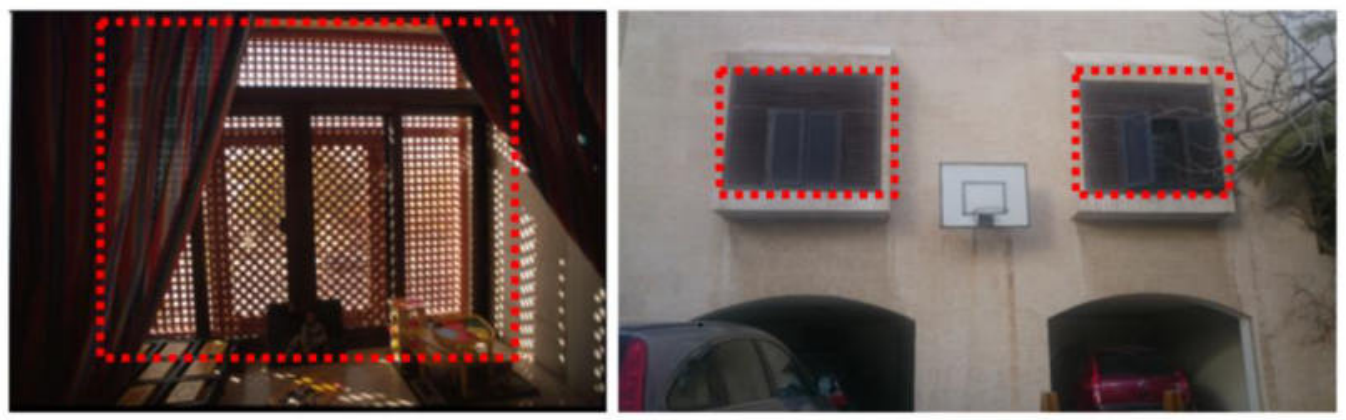

Figure (3)

The wide windows that view the outside as part of the relationship of the body with the outside circumstances, Al-Hammadi, Nesma, (2015), Survey of the Contents and Elements of Islamic Architecture in Contemporary Housing in Amman-Jordan (Amman, p. 11). 

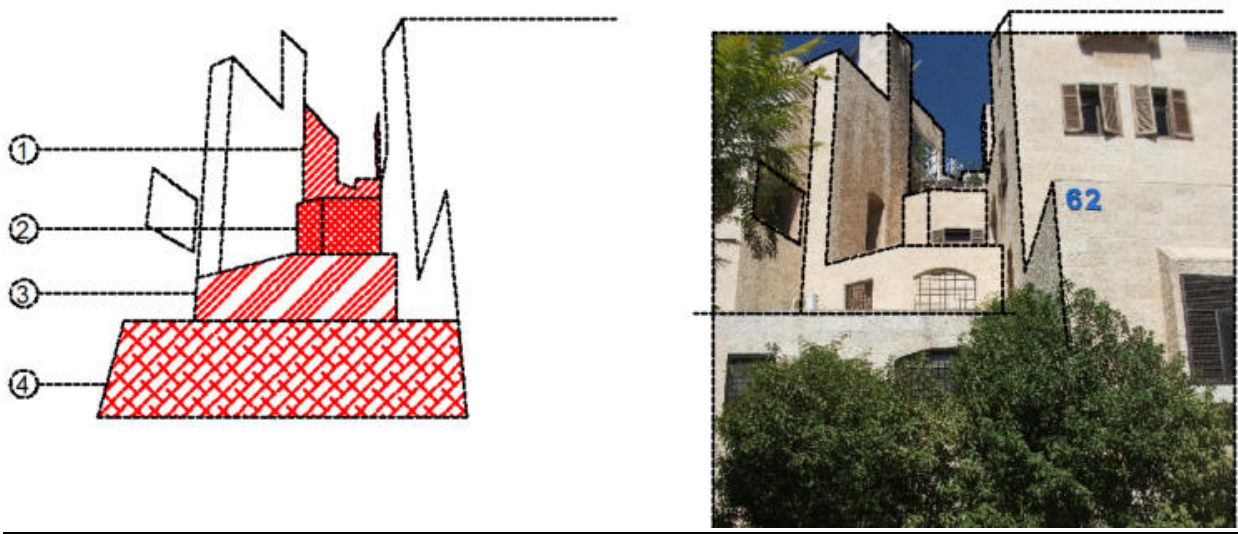

Figure (4)

The figure shows the gradient between the blocks, suggesting the rhythm and harmony between the overlapping blocks one above the other.

1. The first level

2. The second level

3. The third level

4. The fourth level

The four levels show the gradient in the formal organization of blocks in the dwelling.

(Researcher analysis)
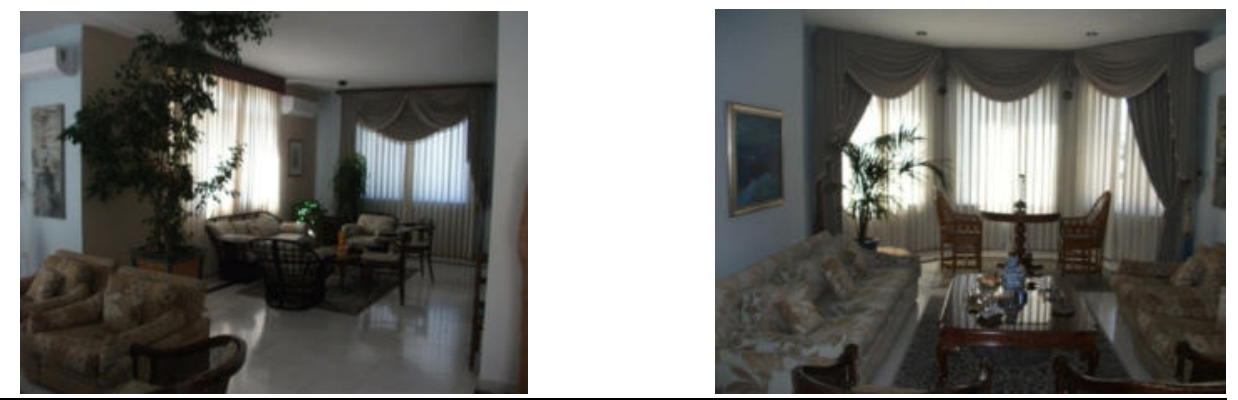

\section{Figure (5)}

An internal scene shows the distribution of the inner space as an emotional extension that integrates the special spaces with each other.

(The researcher's photography)
Figure (6)

Interior view of the lounge

Demonstrates the formal distribution and monochromatic pattern of interior walls (The researcher's photography)

1. The dwelling is inseparable from the self in terms of the visual formation of the blocks and shapes; rather, the house itself and the body are intertwined with the memories and the visual nature of the human consciousness which is shaped in the mind through the visual relations represented in front of me. Therefore, the scenes of familiarity and the sense of beauty of what we see are a transcendent sense of what we see it inseparable from it.

2. The sense of familiarity, sense and feeling of dwelling is not only the result of childhood memories; it may also be generated by the fact that the dwelling places us in the form of its 
phenomena. Thus, the shape of the rooms in its central depressions and the harmony of form, color and texture are those that motivate us to enjoy the dwelling, and thus arranged by consensus and harmony to achieve familiarity.

3. The basic problem in modern housing is that it is devoid of spirit and life because it expresses a box or a case according to the description of Pashlar, in the sense that it lacks our sense of existence. This confirms that existence is connected to this world and the dwelling expresses a unique relationship between the self and the subject, Which is achieved through what we see and observe, which gives me more space to connect to my space and public space, and I can form these relationships in a manner consistent of the subject with the self.

4. The dwelling is a verifiable presence in the outside world as a conscious subject, and it is thus associated with an expressive force in form and content. This establishes the relation between the forms and the existence of man. The spaces, paths, and spatial relations are the work of the human being and the person who expresses them and at the same time they return again to occupy his thought and sense.

5. The availability of formal characteristics in certain patterns and systems and the provision of sufficient internal spaces contribute to a kind of affinity between the self and the subject as a whole (between the inhabitant and the inhabited), which is a necessary objective for the realization of the idea of housing awareness.

6. We see that what Foucault presented in terms of the connection between art with language and words with things is clearly reflected in art in terms of its elements through the four symmetries, but we must say that the art and the inability of the language to express what is in our minds is owned and expressed in the language which is a direct reflection of the conscience through our reading of the visual things, the image even if couldn't take the right to express in the language it has a strength by linking it to the outside world, which is pointed out by Foucault when referring to the sky and earth and stars and water and soil ... Trying to say that this situation what we see is a state of tissue and compatibility despite its repulsion sometimes.

\section{Conclusion}

Focusing on vocabulary related to job performance does not necessarily mean the achievement of higher human needs (such as familiarity, surprise, pleasure, and housing); But the visual sense and spatial characteristics of the dwelling, is what drives one to think about it and thus achieve those needs. The availability of formal characteristics in certain patterns and systems and the provision of adequate internal spaces contribute to a kind of affinity between the self and the subject as a whole (between the inhabitant and the inhabited) which is a goal necessary to achieve the idea of housing awareness, thus, there is a correspondence between the visual form and the scenes, and this is a sign of harmony and harmony in its closeness and similarity.

\section{References}

Abu Rayan, M. (1989). Philosophy of Beauty and the Origin of Fine Arts, Alexandria, Dar Al Maarifa, p. 3.

Al-Nouri, E. (1970). Art, Science and Beauty, The Small Encyclopedia, a cultural series dealing with various sciences, arts and literature, the House of Public Cultural Affairs, Baghdad.

Arvon, H. (1982). The Marxist Aesthetic, p. 6, translated by Jihad Noman, Oweidat Publications, Beirut.

Fisher, E. (2002). Necessity of Art, Translated by Asaad Halim, Hala for Publishing and Distribution, First Edition, Giza

Foucault, M. (1989-1990). Words and Objects, translation by Mataa Safadi et al, Center for National Development, Beirut.

Stolens, J. (1974). Art criticism, its study of aesthetics and philosophy, translated by Fouad Zakaria, Cairo, Ain Shams University Press.

Zakaria, I. (1977). The Problem of Art, Contemporary Philosophical Problems, Egypt Printing House, Cairo 